\title{
Sustainable Commercial Vegetable Production with Minimal Use of Synthetic Fertilizers and Pesticides
}

\author{
Victor A. Wegrzyn \\ Department of Plant and Soil Science, California State Polytechnic Universiy, Pomona, CA 91768
}

\begin{abstract}
Sustainable production systems are characterized as systems that can be physically and biologically maintained in perpetuity, can avoid adverse environmental and health problems, and can be economically profitable. Organic vegetable production systems are one example of sustainable farming enterprises. In California, organic production and postharvest handling techniques are closely defined by legislation. Of the several grower groups representing organic farmers in the state, the California Certified Organic Farmers is the largest, representing 382 growers that farmed a total area of 10,375 ha in 1988. Of these, 200 growers are vegetable producers. Another organization active among organic growers in California, as well as Mexico, Central American countries, and the Caribbean, is the Organic Crop Improvement Association. Marketing organizations such as the Nutri-Clean Program, which tests produce for pesticide residues and certifies specific residue standards, and the Organic Market News and Information Service facilitate the sale of organic produce in California. Cultural practice information for organic vegetable production is difficult to find, particularly techniques that would allow a grower to switch from conventional to organic production. University researchers and extension workers have so far been of little help, although the Univ. of California Sustainability Program at Davis is beginning research and education activities. Funding for these activities is inadequate, and the program is understaffed. There is need for long-term, interdisciplinary, on-farm studies to study organic production techniques in a realistic setting. At present, the reward system in place in land-grant institutions offers little encouragement to researchers to engage in this kind of work. There are formidable obstacles to increasing the use of organic materials for crop fertilization. The nutrient content of the state's manure and organic waste supplies is probably insufficient to meet the fertility needs of California's crops. In addition, since the majority of land currently producing vegetable crops in California is leased, long-term soil fertility investments are a risky undertaking.
\end{abstract}

\section{Sustainable Commercial Vegetable Production with Minimal Use of Synthetic Fertilizers and Pesticides: A Postlude}

\author{
H.C. Wien \\ Department of Vegetable Crops, Cornell University, Ithaca, NY 148.53
}

The foregoing colloquium chronicles the significant shift in perception that has occurred among research and extension workers in vegetable crops in the recent past. Reducing or eliminating pesticides has changed from an impossible, impractical, and backward idea to a major legitimate motivating force in agricultural research and extension that is now receiving a small amount of funding. In 1988, the National Research and Extension Program on Low-input Sustainable Agriculture made $\$ 3.9$ million available; the program continued in 1989. Related fundamental research has been funded by USDA Competitive Grants, the National Science Foundation, and private industry/public institution partnerships, particularly in the biotechnology area. In addition, some states, such as California, have sponsored research and extension initiatives in sustainable agriculture.

The colloquium speakers indicated that the goal of designing management systems that reduce pesticides and synthetic fertilizers cannot simply be attained by duplicating the mixed farm enterprises of the past century. The presentations show that we need a much more sophisticated and detailed understanding of the agricultural ecology, soil fertility status and nutrient transformations, pest and predator populations and their dynamics, than we have ever had, if we are to succeed in lowering adverse impacts of vegetable production on the environment.

Although some agricultural support industries have expressed concern that the impending restrictions on the use of synthetic pesticides would greatly damage their livelihood, the colloquium speakers have highlighted many opportunities for commercial exploitation. Biological pesticides, crop and cover crop cultivars with weed suppression or allelopathic properties, and new soil cover and weed suppression materials are just a few of the kinds of inputs that could find a ready market. The presentations also imply, however, that reduction of synthetic fertilizers and pesticides will not automatically mean adoption of low-input agriculture. The cost of development of the new biological pesticides, for example, is not likely to make them inexpensive.

The advent of the "biological era" carries with it not only a new set of technologies, but, as Wegrzyn and Kelly stated, a need to adjust the methodology used by horticultural research and extension workers. In the area of research, more long-term, field-scale investigations that compare conventional to reduced pesticide systems will be needed (Steiner et al., 1986; Vereijken, 1986). Since fertility management practices impact on the efficacy of pest control measures and vice versa, subsidiary "satellite" experiments may be needed to investigate particular interactions (C.P. Staver, personal communication). Economic analyses of conventional and reduced pesticide systems must be conducted, not only to compare costs of inputs and returns, but also to assess differences in risk of groundwater pollution, erosion-caused loss of topsoil, etc.

ASHS could foster the trend toward reducing synthetic pesticide and fertilizer inputs by encouraging the publication of studies dealing with long-term, more holistic research projects, as has recently been done by the American Society of Agronomy through the launching of the Journal of Production Agriculture. In addition, ASHS Working Groups should continue to organize workshops and colloquia on topics such as the following:

1) Conversion from conventional to organic vegetable production; 2) low pesticide production systems for particular crops; 3 ) the economics of organic fertilizer sources; 4) teaching undergrad- 